\title{
Normas de Segurança do IQ / UNICAMP
}

\section{Capítulo 1 - Finalidade e Aplicação}

1.1. Essa norma determina os requisitos básicos para a proteção da vida e da propriedade nas dependências do Instituto de Química da UNICAMP, onde são manuseados produtos químicos e equipamentos.

1.2. Essa norma se aplica a todas as pessoas alocadas no Instituto de Química (docentes, funcionários, alunos de graduação, pós-graduação, bolsistas de iniciação científica e pesquisadores) e também àquelas que não estejam ligadas ao mesmo, mas que tenham acesso ou permanência autorizadas, conforme o capítulo II dessa norma, às dependências do IQ/UNICAMP.

\section{Capítulo 2 - Acesso e Permanência}

\subsection{Finalidade}

Esse capítulo tem por finalidade permitir o controle de todas as pessoas, funcionários do IQ/UNICAMP ou não, no tocante à questão do acesso e permanência no Instituto, com especial ênfase aos trabalhos realizados fora do horário administrativo.

2.2. Docentes, funcionários, alunos de graduação e pós-graduação, bolsistas de iniciação científica e pesquisadores

2.2.1. Nos finais de semana o acesso de docentes, funcionários, alunos de pós-graduação, bolsistas de iniciação científica e pesquisadores é controlado pelas entradas principais do IQ/UNICAMP (Bloco A,D,I), e todas as pessoas devem assinar o livro de registro na entrada dos blocos.

2.2.2. É proibido trabalhar sozinho nos laboratórios fora do horário administrativo e em finais de semana, em atividades que envolvam elevados riscos potenciais.

2.2.3. É proibido o acesso e permanência de funcionários que não estejam alocados na Unidade Piloto. $\mathrm{O}$ acesso pode ser permitido somente por necessidade expressa de serviço. 
2.2.4. É proibido o acesso e permanência de pessoas estranhas ao serviço, nas áreas de risco do Instituto (laboratórios de Pesquisa e Ensino, Planta Piloto, Oficinas).

2.2.5. O técnico de Segurança do IQ no exercício de suas funções tem acesso livre a todas as dependências do Instituto.

\subsection{Visitantes}

2.3.1. Os visitantes somente poderão ter acesso e permanência nas dependências do IQ pela entrada do Bloco A, onde a segurança solicitará autorização do setor a ser visitado, e procederá a identificação e registro no livro de controle.

2.3.2. Os visitantes que se dirigirem a biblioteca serão identificados diretamente pelo pessoal ali alocado.

2.3.3. Todos os itens descritos nesta norma são válidos para os visitantes, sendo que o acesso e permanência aos laboratórios e Unidade Piloto somente poderão ser efetuados após receberem instrução de segurança dos responsáveis das respectivas áreas.

Capítulo 3 - Conduta e Atitudes

\subsection{Finalidade}

Esse capítulo tem por finalidade delinear a forma de conduta e atitudes de todas as pessoas, docentes, funcionários e alunos do IQ ou não, de forma a contribuir para minimizar os riscos das atividades efetuadas.

\subsection{Gerais}

3.2.1. É proibido o uso de aparelho de som, tais como rádios, toca-fitas e CDs em quaisquer áreas do IQ que envolvam atividades de risco.

3.2.2. É proibido fumar nos Laboratórios, Almoxarifado e Unidade Piloto.

3.2.3. É proibido a ingestão de qualquer alimento ou bebida nos Laboratórios, Almoxarifado e Unidade Piloto.
3.2.4. É proibido a circulação de bicicletas, skates, patins e afins pelos corredores do Instituto.

3.2.5. É obrigatória a comunicação à Comissão de Segurança sobre reformas e obras nas dependências do Instituto para que seja efetuado o acompanhamento do cumprimento das Normas de Segurança.

Capítulo 4 - Trabalho em Laboratórios e Unidade Piloto

\subsection{Finalidade}

Este capítulo tem por finalidade delinear procedimentos básicos de trabalho em laboratórios, Unidade Piloto e Almoxarifado pertencentes ao IQ.

\subsection{Gerais}

4.2.1. É obrigatória a manutenção de áreas de trabalho, passagens e dispositivos de segurança livres e desimpedidos.

4.2.2. É obrigatório que as saídas de emergência estejam desimpedidas.

4.2.3. É obrigatório o conhecimento da localização dos extintores de incêndio, dos conjuntos de chuveiro de emergência /lava-olhos, mangueiras de emergência e das saídas de emergência por parte dos colaboradores em suas respectivas áreas de trabalho.

4.2.4. É obrigatória a inspeção periódica (quinzenal) dos conjuntos de chuveiro de emergência/lava-olhos, que é de responsabilidade do técnico alocado no laboratório, almoxarifado e Unidade Piloto, e comunicação ao técnico de segurança de eventuais irregularidades.

4.2.5. É obrigatória a inspeção periódica (trimestral) do estado de conservação dos frascos e embalagens de reagentes estocados no Almoxarifado do IQ que é de responsabilidade dos funcionários do almoxarifado, dando ênfase aos frascos de metais alcalinos e comunicação ao técnico da Comissão de Segurança de eventuais irregularidades.

4.2.6. É obrigatório o uso de óculos de segurança e botas de segurança na Unidade Piloto, oficinas e áreas de risco 
do almoxarifado

4.2.7. É recomendado, quando do desenvolvimento de tarefas nos laboratórios e Unidade Piloto, fazer uma avaliação da necessidade do porte ou uso da máscara tipo Combitox. Em cada setor, acima citado, deverá haver no mínimo duas máscaras Combitox em local de fácil acesso e devidamente sinalizado.

4.2.8. É recomendado que, quando da realização de atividades de elevado risco, os demais membros do laboratório e os vizinhos sejam notificados.

4.2.9. É obrigatório o uso de luvas e capela com exaustão para descarte e pré-lavagem de recipientes com produtos químicos. Em casos da não existência de capela, usar avental de PVC, protetor facial, e desenvolver a tarefa em local ventilado e seguro.

4.2.10. É obrigatória a rotulagem de recipientes contendo produtos químicos, que deverá conter a classificação de riscos dos produtos químicos, de acordo com a norma específica.

4.2.11. É recomendado se manter a menor quantidade possível de produtos químicos nos laboratórios e Unidade Piloto.

4.2.12. É proibido deixar acumular recipientes, contendo ou não produtos químicos, em bancadas, pias e capelas.

4.2.13. É obrigatório o uso de avisos simples e objetivos para sinalização de condição anormal (ex.: obras no local, rejeitos esperando descarte, instalação de equipamentos, manutenção periódica ou preventiva).

4.2.14. É obrigatória a comunicação de qualquer acidente à Comissão de Segurança. Em caso de lesão corporal de qualquer natureza, encaminhar a vítima diretamente ao Pronto Socorro do Hospital Universitário.

4.2.15. É obrigatória a comunicação de situações anormais, quer de mau funcionamento de equipamentos, vazamento de produtos, falha de iluminação, ventilação ou qualquer condição insegura, aos responsáveis pelo setor para imediata avaliação dos riscos. Esta avaliação deve ser registrada em documento apropriado.

4.2.16. É obrigatório o uso de máscara contra pó no manuseio de sólidos pulverizados nos laboratórios, Unidade Piloto, Almoxarifado e oficinas.

4.2.17. É obrigatório o uso de peras de borracha na aspiração de líquidos por pipetagem.
4.2.18. É obrigatório o uso de botas de segurança com biqueira de aço no manuseio de objetos pesados.

4.2.19. É obrigatório o uso de inclinadores e carrinhos de transporte no manuseio de objetos pesados.

4.2.20. É obrigatória a sinalização de superfícies e objetos quentes nos laboratórios e Unidade Piloto.

4.2.21. É obrigatória a utilização de luvas isolantes no manuseio de superfícies e objetos quentes, e luvas de raspa de couro no manuseio de ferramentas cortantes e pesadas.

4.2.22. É obrigatório que os materiais/equipamentos enviados para manutenção sejam descontaminados em seus locais de origem pelo solicitante do serviço.

4.2.23. É obrigatório que todas as amostras enviadas aos laboratórios estejam devidamente identificadas e contenham informações sobre seu risco e forma adequada de manuseio.

\subsection{Específicas:}

\subsubsection{Laboratórios}

4.3.1.1. É obrigatório o uso de avental longo de algodão fechado sobre a roupa, o uso de óculos de segurança, de qualquer calçado fechado e de calça comprida nos trabalhos realizados nos laboratórios didáticos. É recomendado o uso dos mesmos em laboratórios de pesquisa. A critério de cada responsável por laboratório de pesquisa, essa recomendação poderá ser transformada em obrigatoriedade.

4.3.1.2. É obrigatório o manuseio de produtos químicos tóxicos e corrosivos em capela com exaustão ligada, e o uso de luvas.

4.3.1.3. É recomendado o uso de máscara com filtro apropriado no laboratório durante a pesagem de produtos tóxicos e/ou voláteis nas balanças analíticas. Nos casos de produtos de maior toxicidade, o laboratório deverá ser evacuado até a conclusão da pesagem.

4.3.1.4. É obrigatório o uso de luvas isolantes e frascos apropriados no transporte de Nitrogênio líquido nos laboratórios.

4.3.1.5. É proibida a armazenagem de cilindros de gases 
no interior dos laboratórios, em particular aqueles de gases inflamáveis e GLP. Poderá ser permitido somente em casos excepcionais, observando todos os itens descritos a seguir.

- Manter o cilindro fixado por meio de correntes, isto é, com cinta de segurança.

- Não manusear cilindros de gases comprimidos utilizando a válvula como ponto de apoio.

- Utilizar o procedimento de rolagem de cilindros somente para pequenos ajustes de posição. Nos demais casos, utilizar os carrinhos apropriados.

4.3.1.6. É obrigatório manter, no interior das casas de gases, somente cilindros presos a suas devidas cintas de segurança e observando a compatibilidade entre os gases armazenados.

4.3.1.7. É recomendado extremo cuidado na utilização de instrumentos que emitam raios $\mathrm{X}$, laser, ultravioleta e infravermelho no sentido de se prevenir danos de radiação.

4.3.1.8. É obrigatório o uso de protetor facial e avental de PVC em operações que envolvam o manuseio de recipientes sob alto vácuo ou aqueles fortemente pressurizados.

4.3.1.9. É proibido o uso de mistura sulfocrômica em todos os laboratórios de Ensino e Pesquisa do Instituto e na Planta Piloto. Poderão ser estabelecidas algumas exceções, mediante parecer da Comissão de Segurança do IQ.

\subsubsection{Unidade Piloto.}

4.3.2.1. É obrigatório o uso de avental longo de algodão fechado sobre a roupa, o uso de óculos de segurança, calça comprida e botas de segurança na Unidade Piloto.

4.3.2.2. É obrigatório o uso de abafador de ruído na Unidade Piloto.

\subsubsection{Oficinas}

4.3.3.1. É obrigatório o cumprimento das Normas de Segurança específicas que serão definidas pela Comissão de Segurança,. antes de todo trabalho que ofereça risco
Capítulo 5 - Estocagem de produtos químicos, rejeitos e materiais

diversos

\subsection{Finalidade:}

Esse capítulo tem por finalidade delinear procedimentos básicos de estocagem de produtos químicos e materiais no IQ/UNICAMP.

\subsection{Estocagem de produtos químicos}

5.2.1. É obrigatório que os produtos estocados estejam divididos de acordo com as classificações de risco.

5.2.2. É obrigatória a manutenção de inventário atualizado dos produtos químicos estocados.

5.2.3. É recomendado que a estocagem e manuseio de produtos químicos ocorra somente após preparação e divulgação das Fichas de Emergência.

\subsection{Rejeitos}

5.3.1. É obrigatória a observação das regras de compatibilidade, divulgadas pela Comissão de Segurança, nas separações dos rejeitos líquidos dos laboratórios (solventes orgânicos).

5.3.2. É recomendado não estocar rejeitos nos Laboratórios e Unidade Piloto.

5.3.3. É obrigatória a identificação completa dos recipientes contendo rejeitos. Os rótulos devem conter todos os rejeitos adicionados ao recipiente.

\subsection{Materiais diversos}

5.4.1. É proibido acumular materiais sobre bancadas e pias. Todo material que não estiver em uso deve ser guardado limpo, em lugar apropriado.

5.4.2. É obrigatório providenciar imediatamente o conserto dos materiais danificados. Materiais sem condição de reaproveitamento, deverão ser descartados imediatamente, respeitando-se as regras aplicáveis ao Patrimônio da Universidade.

5.4.3. É obrigatória a manutenção de inventário de materiais nos almoxarifados. 
5.4.4. É obrigatório que os vidros quebrados, que não possam ser reaproveitados, e os frascos de solvente descartados sejam colocados nos tambores localizados ao lado do depósito de gases.

\section{Capítulo 6 - Descarte de Rejeitos}

\subsection{Finalidade}

Esse capítulo tem por finalidade estabelecer um procedimento para o descarte de rejeitos oriundos das atividades realizadas no IQ.

6.1.1. O responsável pelo laboratório deverá definir uma área no seu laboratório para descarte de resíduos, da qual o pessoal da Segurança do IQ será informado e à qual terá acesso. O gerenciamento dessa área é de responsabilidade do responsável pelo laboratório.

\subsection{Gerais}

6.2.1. É obrigatório que os rejeitos oriundos dos Laboratórios e da Unidade Piloto estejam devidamente identificados e acompanhados pelo Formulário Interno de Descarte ou Ficha de Emergência devidamente preenchidos. Entende-se como devidamente identificados o seguinte: Todos os frascos conterão rótulo com as seguintes informações:

a. Composição qualitativa do rejeito.

b. Data.

c. Nome do responsável.

6.2.2. Não serão aceitos para descarte os rejeitos que não estiverem de acordo com o item 6.2.1 dessas Normas.

6.2.3. É obrigatório que os rejeitos oriundos dos Laboratórios de pesquisa/ensino/Unidade Piloto, sejam tratados previamente.

6.2.4. É obrigatório que os métodos de tratamento e descarte dos rejeitos oriundos das disciplinas experimentais sejam fornecidos previamente.

6.2.5. É obrigatório manter organizados e em local adequado os rejeitos estocados provisoriamente nos Laboratórios e Unidade Piloto.

6.2.6. Não serão aceitos para descarte rejeitos líquidos contendo sólidos em suspensão.

\section{Capítulo 7 - Responsabilidades}

\subsection{Finalidade}

Esse capítulo tem por finalidade estabelecer as responsabilidades pelo cumprimento de alguns itens destas Normas.

\subsection{Responsabilidades gerais}

7.2.1. A Comissão de Segurança do IQé encarregada pela manutenção, alteração e revisão periódica destas Normas, encaminhando-as para a Diretoria para aprovação da Congregação.

7.2.2. É de responsabilidade de todo o pessoal alocado no IQ cumprir e fazer cumprir os itens previstos nestas Normas.

\subsection{Responsabilidades Específicas.}

7.3.1. É de responsabilidade do Técnico de Segurança o gerenciamento interno dos EPI's fornecidos pelo SST.

7.3.2. É de responsabilidade exclusiva dos docentes o gerenciamento dos rejeitos nos laboratórios de pesquisa, a quem caberá informar à Comissão de Pós-Graduação e a Diretoria sobre o descarte dos rejeitos de cada aluno de pós-graduação, bolsista de iniciação científica e pesquisador que deixe o Instituto.

7.3.3. É tarefa exclusiva dos docentes responsáveis pelas disciplinas experimentais, o fornecimento prévio dos métodos e procedimentos para separação, tratamento e descarte dos rejeitos gerados.

7.3.4. É de responsabilidade dos técnicos dos laboratórios de graduação, Unidade Piloto, pesquisa e do técnico da Comissão de Segurança do IQo tratamento, organização, controle, preenchimento de formulários e descarte dos rejeitos gerados nos respectivos laboratórios.

\subsection{5. É de responsabilidade do Técnico da Comissão de Segurança}

7.3.5.1. Verificação da aplicação das Normas de SegurançaIQ com comunicação de irregularidades à Diretoria-IQ

\subsubsection{Gerenciamento dos Rejeitos do IQ}


7.3.5.2.1. Apoiar alunos e funcionários no descarte de resíduos;

7.3.5.2.2. Fornecer procedimentos padrões, quando existentes, para tratamento dos resíduos;

7.3.5.2.3. Fornecer os frascos (bombonas de PVC), devidamente identificados, para os laboratórios realizarem os descartes dos solventes de acordo com a discriminação previamente elaborada pela Comissão de Segurança;

7.3.5.2.4. Organizar o descarte de acordo com os formulários entregues;

7.3.5.2.5. Acompanhar o técnico do laboratório no descarte;

7.3.5.2.6. Coordenar o armazenamento dos resíduos;

7.3.5.2.7. Providenciar o transporte e a documentação para a incineração dos resíduos;

7.3.5.2.8. Manter contato com a CETESB e a empresa que efetua a incineração;

7.3.5.2.9. Providenciar a incineração dos resíduos estocados;

\subsubsection{Supervisão e Controle dos Equipamentos de Segurança do IQ}

7.3.5.3.1. Verificação periódica dos prazos dos extintores de incêndio do Instituto e providenciar a troca dos vencidos, ou prestes a vencer;

7.3.5.3.2. Checagem periódica do sistema de alarme do Instituto, realizando: Testes de funcionamento, com aviso prévio do pessoal da área onde o teste será realizado; Checagem periódica da bateria do sistema no-break do alarme de segurança; Comunicação imediata das eventuais falhas eletrônicas à Oficina eletrônica do Instituto

7.3.5.3.3. Manutenção após comunicação de irregularidades dos lava-olhos e chuveiros de emergência dos laboratórios;

7.3.5.3.4. Manutenção periódica das portas de emergência do Instituto;

7.3.5.3.5. Manutenção e verificação periódica do funcionamento das capelas;
7.3.5.3.6. Verificação e reposição periódica de máscaras de gás, dos filtros das máscaras e dos armários de medicamentos alocados nos laboratórios;

7.3.5.3.7. Distribuição dos equipamentos de segurança para os funcionários e docentes do Instituto;

7.3.5.3.8. Distribuição e controle das requisições de material de segurança do Instituto e aqueles requisitados ao SST;

7.3.5.3.9. Controle dos estoques de material de segurança e pela solicitação de reposição;

\subsubsection{Treinamento de Segurança}

7.3.5.4.1. Responsável pela organização do treinamento de segurança para os funcionários e alunos do Instituto (combate a incêndio e uso de extintores);

7.3.5.4.2. Responsável pela organização do treinamento de primeiros socorros para os funcionários e alunos do Instituto;

7.3.5.4.3. Responsável pelo treinamento no uso de máscaras autônomas dos funcionários e alunos designados por esta Comissão;

7.3.5.4.4. Responsável pelo treinamento no uso de máscaras de segurança e equipamentos de proteção individual para todos os funcionários e alunos do Instituto;

7.3.5.4.5. Apoio total nos cursos oferecidos pelo Instituto no âmbito de Segurança (QG362 e QGs), sempre sob orientação da Comissão de Segurança;

7.3.5.4.6. Responsável pelas providências necessárias a realização do treinamento e reciclagem da Brigada de Incêndio do IQ.

\subsubsection{Gerenciamento da Segurança Interna}

7.3.5.5.1. Responsável por relatar as ocorrências internas de acidentes, providenciando fotos, remoções de entulhos, etc, de comum acordo com a CIPA setorial;

7.3.5.5.2. Responsável pelo contato direto com os Membros da Brigada de Incêndio do IQ;

7.3.5.5.3. Responsável pela interação técnica com o SST- 
CS/IQ-Cipa Setorial;

7.3.5.5.4. Responsável pela sinalização das áreas sob risco no IQ;

7.3.5.5.5. Responsável pela sinalização de segurança do Instituto, afixando placas e avisos que alertem para os riscos das diferentes áreas do Instituto;

7.3.5.5.6. Responsável pela manutenção da sinalização de segurança do Instituto. 